\title{
Telessaúde e Idosos Diabéticos: Narrativa de Aspectos Educacionais sobre a Covid-19
}

\author{
Nathalia Priscilla Oliveira Silva Bessa, ${ }^{1}$ Bartolomeu Fagundes de Lima Filho, ${ }^{2}$ \\ Rachel Naara Silva de Souza, ${ }^{2}$ Ana Clara Teixeira Fernandes, ${ }^{2}$ \\ Marcello Barbosa Otoni Gonçalves Guedes, ${ }^{2}$ \\ Fabrícia Azevedo da Costa Cavalcanti²
}

\section{RESUMO}

Pacientes idosos diabéticos são um segmento de risco para complicações da Covid-19, necessitando, assim, de diferentes estratégias de cuidado à saúde, como a telessaúde, durante a pandemia. O conhecimento acerca desta doença é capaz de facilitar a tomada de decisão quanto à busca pela assistência adequada. Dessa forma, o objetivo do estudo foi investigar o conhecimento de idosos diabéticos em relação à Covid-19 por meio da análise de suas narrativas. Trata-se de um estudo transversal, observacional, descritivo, com abordagem qualitativa e quantitativa com nove idosos diagnosticados com Diabetes Mellitus tipo 2. Os participantes foram entrevistados via telefone sobre o conhecimento quanto aos sintomas, formas de transmissão e prevenção da Covid-19. Em seguida foram capacitados sobre o tema e questionados sobre suas percepções acerca dessas orientações recebidas. Observou-se que cerca de $66,7 \%$ eram do sexo feminino, a média etária foi de $68,55( \pm 2,55)$ e todos os participantes relataram informações compatíveis com as apresentadas pelo Ministério da Saúde. Além disso, os idosos consideraram como extremamente relevantes as informações fornecidas pelos pesquisadores sobre esse vírus.

Palavras-chave: Covid-19; telessaúde; diabetes mellitus tipo 2.

\section{TELEHEALTH AND DIABETIC ELDERLY: NARRATIVE OF EDUCATIONAL ASPECTS ABOUT COVID-19}

\section{ABSTRACT}

Elderly diabetic patients are a risk segment for complications of Covid-19, thus requiring different health care strategies, such as telehealth, during the pandemic. Knowledge about this disease is able to facilitate decision-making regarding the search for adequate assistance. Thus, the objective of the study was to investigate the knowledge of diabetic elderly in relation to Covid-19 through the analysis of their narratives. This is a cross-sectional, observational, descriptive study, with a qualitative and quantitative approach with 9 elderly people diagnosed with Type 2 Diabetes Mellitus. Participants were interviewed via telephone about knowledge about the symptoms, forms of transmission and prevention of Covid-19. Then they were trained on the topic and were asked about their perceptions about these guidelines received. It was observed that about $66.7 \%$ were female, the average age was 68.55 ( \pm 2.55 ), and all participants reported information compatible with that presented by the Ministry of Health. In addition, the elderly considered the information provided by researchers about this virus to be extremely relevant.

Keywords: Covid-19; telehealth; diabetes mellitus type 2.

RECEBIDO EM: 8/6/2020

MODIFICAÇÕES SOLICITADAS EM: 18/11/2020

ACEITO EM: 20/11/2020

\footnotetext{
${ }^{1}$ Autora correspondente. Universidade Federal do Rio Grande do Norte - UFRN. Av. Sen. Salgado Filho, 3000 - Lagoa Nova, Natal/RN, Brasil. CEP 59064-720. http://lattes.cnpq.br/5802240351333531. https://orcid.org/0000-0002-3160-8102. nathyzinhasilva@gmail.com

2 Universidade Federal do Rio Grande do Norte - UFRN. Natal/RN, Brasil.
} 


\section{INTRODUÇÃO}

O coronavírus foi descrito pela primeira vez em 1966 por Tyrell e Bynoe, e possui quatro subfamílias, a saber: alfa, beta, gama e delta, que, em comum, causam doenças respiratórias, desde casos brandos e leves até complicações mais severas, como a síndrome respiratória aguda grave (Sars) (SANAR MED, 2020). No final de 2019, um novo coronavírus, o Sars-CoV-2, conhecido como Covid-19, epi-centrado na província Wuhan, na China, foi responsável pela terceira manifestação grave da transmissão do vírus para humanos (BORNSTEIN et al., 2020; VELAVAN; MEYER, 2020), declarada pandemia no dia 11 de março de 2020 pela Organização Mundial de Saúde (OMS), e já soma mais de 344.454 mortes (WHO, 2020). Destas, a coexistência de comorbidades e a população idosa lideram os dados, com 50-75\% dos casos (SINGHAL, 2020).

Dentre essas comorbidades, a doença crônica associada mais comum é o diabetes mellitus (BULUT; KATO, 2020; GE et al., 2020; RICHARDSON et al., 2020; SOHRABI et al., 2020), ligado à gravidade de todas as três infecções conhecidas por coronavírus humano patogênico, com uma proporção geral de 5,3\% a 20\% nos casos da Covid-19 (VELAVAN; MEYER, 2020).

Pacientes diabéticos, em todas as suas formas, têm suscetibilidade aumentada e maior gravidade da doença após infecção por Sars-CoV-2 (BORNSTEIN et al., 2020). Ou seja, a presença de diabetes em indivíduos contaminados com a Covid-19 aumenta duas vezes a chance de mortalidade quando comparado ao indivíduo não diabético (índice de mortalidade de até 7,3\% vs 0,9\%) (BULUT; KATO, 2020; KUMAR et al., 2020; SBD, 2020a; VELAVAN; MEYER, 2020). Viu-se que, quanto maior o nível de glicose no sangue captado pelas células de defesa do corpo, maior a fonte de energia que permite ao vírus se replicar e, em resposta à crescente carga viral, ocorre a morte de células pulmonares (CODO et al., 2020; WANG et al., 2020).

Dessa forma, o controle glicêmico é fundamental para que pacientes diabéticos com Covid-19 possuam uma recuperação rápida e com poucos déficits, uma vez que existe um ciclo vicioso entre a presença de DM2 e a Covid-19, de modo que a Covid-19 gera uma desregulação na glicemia, piorando o quadro de DM2, que, por sua vez, piora o quadro de Covid-19 (PAL; BHADADA, 2020; PERIC; STULNIG, 2020).

Por suas taxas de transmissibilidade, internação em unidade de terapia intensiva e em enfermaria, gravidade de doenças e mortalidade, a Covid-19 é atualmente uma preocupação internacional (BULUT; KATO, 2020). Com RO estimado em 3,28 (mediana de 2,79), revelando um potencial de transmissão sustentado de humano para humano, mesmo que com pequena quantidade de material infeccioso (VELAVAN; MEYER, 2020; ASSOBRAFIR, 2020), o uso de EPIs e a lavagem correta das mãos são capazes de interromper a cadeia de propagação da doença. Neste cenário, diferentes estratégias devem ser instituídas e medidas eficazes estabelecidas, como o isolamento social (HARAPAN et al., 2020; SINGHAL, 2020; SBD, 2020c), com a adequada educação em saúde por meio do teleatendimento, a saber: a telessaúde.

Editora Unijuí - Revista Contexto \& Saúde - ISSN 2176-7114 - v. 21, n. 43, jul./set. 2021 
A Organização Pan-Americana da Saúde (Opas), assim como a OMS, define a telessaúde como a prestação de serviços de saúde em casos nos quais a distância é um fator crítico, possibilitando a realização de diagnóstico, tratamento e prevenção de doenças, pesquisa e avaliação e educação continuada (WHO, 2010).

Atualmente, o crescimento da telessaúde e a sua importância como ferramenta para dar respostas oportunas, já são fatos reconhecidos. As tecnologias de informação e comunicação (TIC) contribuem para melhorar o acesso aos cuidados de saúde, a qualidade do serviço, a eficácia das intervenções e, mediante treinamento e colaboração, as competências dos profissionais (SANTOS et al., 2014; BRASIL, 2020a).

Cientes de que pessoas com diabetes, assim como pacientes cardiopatas, com doenças respiratórias pré-existentes e idosos, compõem segmento de risco para complicações com a infecção, a pandemia da Covid-19 evidenciou a necessidade da expansão do uso de telessaúde e medicina digital para toda a população, em especial a esses indivíduos (CAETANO et al., 2020; SBD, 2020b). Majoritariamente, tem o objetivo de orientar e disseminar informações relevantes das autoridades de saúde a respeito do novo coronavírus (Covid-19), assim como disponibilizar, de forma rápida e dinâmica, orientações pertinentes aos cuidados de prevenção, sinais e sintomas e propagação da doença; a exemplo o telefone 136, do Ministério da Saúde, pelo qual o usuário pode obter respostas para as perguntas mais frequentes, além do gerenciamento de casos leves com aconseIhamento sobre sinais de perigo (BRASIL, 2020b).

Nesse contexto, entender o conhecimento com empoderamento social é de suma importância para que haja a disseminação das informações acerca de uma doença com consequências tão devastadoras como a Covid-19. Uma vez que o idoso conheça os sintomas, a transmissão e a prevenção nesse surto pandêmico, permite a identificação de possíveis casos e isso facilitará seu tratamento, reduzindo o risco de morbimortalidade. Diante do exposto, o objetivo do presente estudo foi investigar o conhecimento de idosos diabéticos em relação à Covid-19 por meio da análise de suas narrativas.

\section{METODOLOGIA}

\section{Delineamento}

Trata-se de um estudo transversal, observacional, descritivo, com abordagem qualitativa e quantitativa.

\section{Aspectos éticos}

O desenvolvimento do estudo atendeu às normativas éticas de estudos com seres humanos, obtendo o parecer número 3.084.420 do Comitê de Ética em Pesquisa com Seres Humanos do Hospital Universitário Onofre Lopes (HUOL), vinculado à Universidade Federal do Rio Grande do Norte (UFRN). O Consentimento Livre e Esclarecido foi obtido por intermédio da concordância em participar por meio do contato telefônico.

Editora Unijuí - Revista Contexto \& Saúde - ISSN 2176-7114 - v. 21, n. 43, jul./set. 2021 


\section{População}

Para a elaboração do presente estudo foi consultada a lista de participantes do Projeto "Influência de um protocolo de realidade virtual no equilíbrio corporal de idosos com diabetes mellitus tipo 2: ensaio clínico randomizado controlado", residentes em Natal/RN e na região metropolitana.

\section{Amostra e critérios de elegibilidade}

Foi dada por conveniência mediante os inscritos no Projeto supradescrito. Foram incluídos no estudo idosos (idade de 65 a 75 anos) com diagnóstico clínico de diabetes mellitus tipo 2 pela American Diabetes Association (GROSS et al., 2002), participantes da reabilitação do equilíbrio corporal no Laboratório de Inovação Tecnológica em Saúde (Lais) do HUOL/UFRN, e que possuíssem um contato telefônico (fixo ou móvel). Ao total, 48 participantes estavam registrados no banco de dados do estudo, porém, para se obter uma amostra significativa para a pesquisa, foram aleatorizados $20 \%$ desta população para participar do estudo, e os demais foram apenas capacitados quanto à Covid-19. Dessa forma, dez participantes foram contatados via ligação telefônica para compor o presente estudo. Foram excluídos da pesquisa os idosos que não atenderam a nenhuma das cinco tentativas de contato telefônico e com déficit auditivo, sem acompanhante/cuidador que pudesse receber as orientações por telefone.

\section{Procedimentos, instrumentos e análise}

O problema definido em questão refere-se ao conhecimento dos participantes sobre os sintomas, formas de transmissão e prevenção da doença Covid-19. Em seguida eles foram capacitados sobre essas características e questionados acerca de suas percepções sobre orientações repassadas pelos pesquisadores sobre estes mesmos aspectos.

Para atender aos objetivos propostos, a metodologia eleita foi a realização de entrevistas via telefone e gravação das respostas emitidas pelos entrevistados. Os idosos foram contatados em horário comercial por um pesquisador devidamente treinado e capacitado para tal.

$\mathrm{Na}$ abordagem qualitativa, para se verificar o nível de conhecimento sobre a Covid-19 dos entrevistados foi elaborado um check-list com base nos dados fornecidos pelo Ministério da Saúde, conforme mostra o Quadro 1. Não foram coletados dados sobre "diagnóstico", "informações para viajantes" e "se o indivíduo ficar doente" para reduzir o número de informes, uma vez que a maioria desses esclarecimentos foram contemplados nos tópicos anteriormente eleitos. Após documentação das respostas, a análise qualitativa foi realizada a partir da interpretação de cada uma delas separadamente (GODOY, 1995). Foi também realizada uma distribuição em nuvem que incluía as palavras que mais se repetiram nas respostas, com o tamanho de cada uma delas proporcional à frequência com que apareciam (PRAIS; ROSA, 2017).

Editora Unijuí - Revista Contexto \& Saúde - ISSN 2176-7114 - v. 21, n. 43, jul./set. 2021 
Quadro 1 - Check-list das orientações relativas à Covid-19 fornecidas por teleatendimento

\begin{tabular}{|c|c|c|}
\hline Sintomas & Formas de Transmissão & Medidas de Prevenção \\
\hline $\begin{array}{l}\text { - Tosse } \\
\text { - Febre } \\
\text { - Coriza } \\
\text { - Dor de garganta } \\
\text { - Dificuldade para } \\
\text { respirar }\end{array}$ & $\begin{array}{l}\text { - Toque do aperto de } \\
\text { mão; } \\
\text { - Gotículas de saliva; } \\
\text { - Espirro; } \\
\text { - Tosse; } \\
\text { - Catarro; } \\
\text { - Objetos ou superfí- } \\
\text { cies contaminadas, } \\
\text { como celulares, me- } \\
\text { sas, maçanetas, brin- } \\
\text { quedos, teclados de } \\
\text { computador, etc. }\end{array}$ & $\begin{array}{l}\text { - Higienizar as mãos com água e sabão } \\
\text { - Ao álcool em gel 70\%; } \\
\text { boca com lenço ou com o braço, e } \\
\text { não com as mãos; } \\
\text { - Evitar tocar olhos, nariz e boca com } \\
\text { as mãos não lavadas; } \\
\text { - Manter uma distância mínima de } 2 \\
\text { - } \text { Evetros de qualquer pessoa; } \\
\text { - não monte contato físico com pessoas que } \\
\text { - Quando doente, evitar contato físico } \\
\text { com outras pessoas, inclusive dentro } \\
\text { de sua própria casa, e fique em casa } \\
\text { até melhorar; } \\
\text { - Higienizar com frequência o celular e } \\
\text { os brinquedos das crianças; } \\
\text { - Não compartilhar objetos de uso } \\
\text { pessoal, como talheres, toalhas, } \\
\text { pratos e copos; } \\
\text { - Manter os ambientes limpos e bem } \\
\text { ventilados; } \\
\text { - Evitar circulação desnecessária } \\
\text { nas ruas, igrejas, supermercados e } \\
\text { bancos; } \\
\text { - Dormir bem e ter uma alimentação } \\
\text { saudável; } \\
\text { - Utilizar máscaras de tecido ao sair } \\
\text { de sua residência, trocando-as, no } \\
\text { máximo, até } 2 \text { horas. }\end{array}$ \\
\hline
\end{tabular}

Fonte: BRASIL, 2020c.

Para a abordagem quantitativa, após identificação, o paciente foi questionado sobre dados socioeconômicos, sexo, idade, estado civil, escolaridade, renda, condição previdenciária, participação social, consumo de álcool e tabaco. Para análise destes dados foi utilizado o software SPSS (versão 20.0, IBM, New York, USA), procedendo com análise descritiva com cálculos de média aritmética e desvio padrão.

Ao final das entrevistas o pesquisador, previamente treinado, forneceu informações padronizadas aos entrevistados referentes aos aspectos de sintomas, formas de transmissão e prevenção para a Covid-19. Por fim, os entrevistados foram questionados sobre sua percepção quanto às informações recebidas. Para a classificação das respostas foi estruturada em escala do tipo Likert, composta da seguinte forma: (0) irrelevantes; (1) pouco relevantes; (2) relevantes; (3) muito relevantes; (4) extremamente relevantes. 


\section{RESULTADOS}

Dos dez idosos contatados via telefone, nove atenderam a ligação e aceitaram participar da capacitação. Dentre eles, a maioria $(66,7 \%)$ era do sexo feminino, a média etária foi de 68,55 ( $\pm 2,55)$, faixa etária predominante de 65-69 anos $(77,8 \%)$, maioria de cor branca $(55,6 \%)$, média de $10,33( \pm 3,93)$ anos de estudo com maioria apresentando ensino pós-elementar (44,4\%), com vida conjugal $(66,7 \%)$, renda média de $R \$ 3499,55( \pm 1458,25)$, aposentados $(66,7 \%)$, com participação social $(66,7 \%)$, maioria não etilista $(77,8 \%)$ e não tabagista (88,9\%).

Com relação aos sintomas, os participantes apresentaram alguns listados pelas orientações do Ministério da Saúde já mencionados e outros que não estão presentes nessas orientações, como nas narrativas seguintes. Ainda, alguns relataram três ou mais sintomas:

"pelo que eu escuto falar é tosse seca, é o cansaço, né. Falta de ar, respiração. Sem paladar, febre, é... moleza no corpo, dói o corpo todo. São esses sintomas que eu já ouvi falar muito" (Participante A. A.).

"eu acho... eu acho que talvez febre, tosse, espirro, é... Dores, dor de cabeça, é... eu vejo sempre sabe assim, falar sobre, mas a gente não decora tudo né... mais ou menos por ai" (participante L. A.).

"tosse, corize, febre, é... dores no corpo e a falta de ar" (Participante V. L.).

Outros participantes restringiram-se a falar poucos sintomas e alguns não condizentes com as orientações do Ministério da Saúde, conforme pode-se verificar adiante:

"É... são sintomas preliminares como gripe né?! É... parecido com a gripe, depois aparece dor no peito, febre, e eu acredito que são esses os sintomas que graças a Deus eu só ouço falar, né? Mas acredito que são esses... Moleza no corpo" (Participante A. S.).

"É... Dor de cabeça... Falta de ar" (Participante M. J.).

Com relação às formas de transmissão, houve participante que relatou a maioria das formas mencionadas no site do Ministério da Saúde:

"através da... da saliva, do ar, gotículas, é... do contato pelas mãos (Participante M. J.).

"através do contato né... É... Com as pessoas que, digamos assim, a pessoa que estiver contaminada espirrar perto de você. É... Você, né, contrair aquele fluxo que solta né perto... O contato da mão... Se por acaso tiver alguém contaminado e você passar a mão e levar o rosto, né? Né nos olhos, no nariz, até passar a mão na boca. Por aí né? É assim que eu entendo (Participante V. L.).

Alguns mencionaram menos formas de transmissão ou, até mesmo, relataram que a transmissão fosse exclusivamente pelo contato:

"Através... Eu creio assim, através da saliva, do contato, né? Do contato" (Participante A. A.).

"É através, é um virus, né?! Através de, é... Das outras pessoas" (Participante J. G.).

"Transmitida do vírus, né? Do contato" (Participante M. S.). 
Já nas formas de prevenção, os participantes alcançaram respostas bem completas, incluindo a maioria dos itens listados nas orientações já descritas:

"É... Antes de... Se eu... Eu não quero chamar, chamar de isolamento, mas se protegendo dentro de casa. Lavando as mãos com água, sabão, se preciso, álcool em gel. Sair apenas quando necessário... Então, acredito que assim há uma maior proteção" (Participante A. S.).

"Ter os cuidados com a higiene... É para manter o isolamento e... Lavar bem as mãos... Usar bastante sabão, bastante água, lavar da forma correta. E no caso de não tá próximo de água e sabão, ter álcool a 70… Também passar da forma correta, e usar máscara... Mas manter sempre... Ter de sair só se necessário mesmo, e manter sempre a distância" (Participante M. J.).

"Para a gente se proteger eu acho que é assim... Lavando as mãos direto, sempre com água e sabão, usar o álcool 70… É... Evitar, assim, as pessoas, a aproximação das pessoas tem que ser de um metro e meio a dois metros de distância. Evitar né, assim... Ficar sempre com a máscara, pra gente ficar livre de tá sentindo, né?! Porque o ar fica poluido com as goticulazinhas; passam, né?! E se alimentar direito, pras defesas ficarem normal também, né... Ter alimentação normal. E acho que dormindo bem a quantia de horas, descansando um pouco cada dia, e por aí vai" (Participante L. A.).

"É... Ficar em longa distância, né, um metro, um metro e meio. Usar máscara, passar álcool nas mãos, a limpeza dentro de casa, né?! É o que eu estou fazendo...estou fazendo isso" (Participante M. S.).

Ainda, apenas um participante mencionou uma única forma de prevenção:

"Se proteger, se ausentar. Ficar em casa" (Participante J. L.).

Quanto à percepção sobre a relevância das orientações, todos os nove participantes (100\%) relataram que acharam as informações "extremamente relevantes". Com relação ao meio de comunicação, sete participantes $(77,8 \%)$ relataram que o meio telefônico foi "extremamente relevante" para passar as informações e dois participantes $(22,2 \%)$ relataram "muito relevante".

Por fim, está representado na Figura 1 uma "nuvem de palavras" com todos os termos falados pelos participantes de forma repetida com sua intensidade e tamanho alterados de acordo com a quantidade de citações feitas pelo "wordclouds.com".

Figura 1 - Nuvem de palavras sobre a Covid-19 por idosos diabéticos

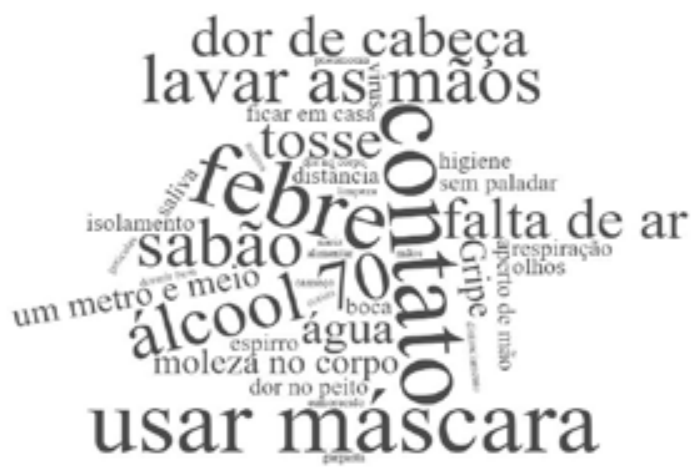

Fonte: Própria do autor. Natal/RN, 2020.

Editora Unijuí - Revista Contexto \& Saúde - ISSN 2176-7114 - v. 21, n. 43, jul./set. 2021 


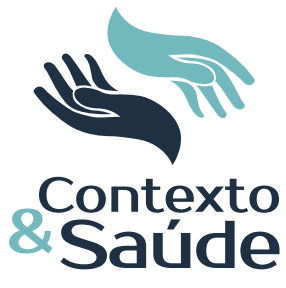

\section{DISCUSSÃO}

Diante da complexidade do processo de envelhecimento humano, com peculiaridades próprias, associada à alta incidência das doenças crônicas, tais como diabetes, e suas repercussões no corpo humano, torna-se evidente a necessidade de atenção específica aos idosos, incluindo ações de prevenção, tratamento e reabilitação (HAMMERSCHMIDT; SANTANA, 2020). No contexto da atual pandemia, no entanto, estratégias diferenciadas devem ser tomadas para que a assistência em saúde da população continue de modo a reduzir o risco de contaminação, principalmente dos mais suscetíveis, como os idosos diabéticos.

Nesse contexto, quanto à análise descritiva do perfil dos idosos desta pesquisa, a maioria possuía hábitos saudáveis com relação ao consumo de álcool e tabaco, sendo este um ponto positivo na prevenção e manejo à Covid-19 (TESTINO, 2020). O bom grau de instrução, serem aposentados e com renda média superior a três salários mínimos, colocam esse grupo de estudo em condição privilegiada para o manejo de condições crônicas e agudas em saúde. Ter uma vida conjugal e participação social adequadas podem também ser fatores de proteção para o cuidado integral das pessoas idosas (GUEDES et al., 2017). Com relação à média de idade, é importante salientar que a amostra não contemplou nenhum idoso longevo.

Levando em consideração esse bom grau de instrução, a telessaúde é uma estratégia de grande valia, pois permite assistência remota e aumenta o número de atendimentos em época de surto, promovendo cuidado com distanciamento social e reduzindo a possibilidade de contágio entre profissional e paciente (OHANNESSIAN; DUONG; ODONE, 2020). A telessaúde em pacientes diabéticos infectados ou não com a Covid-19 pode ser eficaz para o automonitoramento dos casos, para a necessidade de acompanhamento específico desses e para estratégias de educação em saúde (GUPTA; HUSSAIN; MISRA, 2020).

A educação em saúde estabelece uma relação dialógico-reflexiva entre o profissional e o paciente, objetivando a conscientização deste sobre sua saúde e a percepção como participante ativo na transformação de vida (MALLMANN et al., 2015). Ou seja, a educação em saúde é uma prática que permite a transformação dos modos de vida dos indivíduos e da coletividade, itens necessários em situações de pandemia, como a vivenciada na atualidade (MALLMANN, et al., 2015). Além disso, o profissional de saúde, aliado à família e à sociedade, pode ser um sistema de apoio ao idoso que sofre as consequências do isolamento e distanciamento social, por meio de um relacionamento pautado em respeito, verdade e informação (BRASIL, 2014; HAMMERSCHMIDT; SANTANA, 2020).

Em relação ao conhecimento e as informações sobre a Covid-19, os participantes do estudo apresentaram entendimento considerável, e pode-se vincular este achado à boa escolaridade da amostra. No que se refere aos sintomas, todos mencionaram os sintomas básicos listados pelo Ministério da Saúde (MS). Em contrapartida, alguns participantes citaram sintomas que ainda não foram publicados pelo MS, tais como perda de paladar (ageusia), dor de cabeça e dores no corpo. 
A ageusia aguda foi constatada em pacientes com estágio inicial da Covid-19 na forma mais leve da doença, e em pacientes assintomáticos para os sintomas mais conhecidos (YAN et al., 2020). O acometimento desse sintoma foi mais prevalente entre mulheres e indivíduos mais jovens, e o tempo médio de recuperação foi de sete dias (YONGHYUN et al., 2020). Já a dor de cabeça, bem como as dores no corpo, mencionadas nos estudos, como mialgia ou dores musculares, são consideradas sintomas clínicos mais comuns em paciente com Covid-19 (LI et al., 2020; NASCIMENTO et al., 2020).

Ainda, todas as formas de transmissão citadas pelos idosos participantes foram amplamente divulgadas pelo MS. A doença é transmitida por disseminação espacial e pelo trato respiratório, e a dispersão do vírus pode ocorrer depois de espirros, que é capaz de espalhar gotículas de saliva, assim como a tosse e o muco. Por isso, o contato pessoal, como toque ou aperto de mão, contato com objetos e/ou superfícies contaminadas, sucedido de contato com a boca, nariz ou olhos, devem ser evitados (TIAN et al., 2020; MACKENZIE; SMITH, 2020).

Somado a isto, os participantes apontaram as principais formas de prevenção: uso de máscara, higiene das mãos, distanciamento social, entre outros. Vale destacar que apenas uma participante abordou sobre a importância do sono e de uma boa alimentação como fatores profiláticos, itens aliados para manutenção da glicemia. Indivíduos com diminuição na duração do sono ou perturbação dos padrões de vigília, são relacionados à desregulação metabólica (ROSIQUE-ESTEBAN et al., 2018). Além disso, uma boa alimentação diminui os níveis da glicose plasmática, melhora a resistência à insulina e reduz a circunferência abdominal e a gordura visceral, atuando, consequentemente, no perfil metabólico dos triglicerídeos e colesterol (AMORIM; RAMOS; GAZZINELLI, 2018; YUN et al., 2017).

Assim, foi verificado que a telessaúde pode ofertar um atendimento de qualidade, a um menor custo, e também expandir o acesso da população à saúde (SHIGEKAWA et al., 2018). Essa forma de atendimento oferece oportunidade de monitoramento, em qualquer lugar e a qualquer momento, além de reduzir as idas dos pacientes e da família aos atendimentos presenciais, também facilitando os agendamentos de consultas (CHAET et al., 2017). O atendimento remoto tem papel fundamental na educação em saúde, principalmente no que diz respeito ao autogerenciamento de saúde (TUCKSON et al., 2017).

Apesar, no entanto, dos inúmeros pontos positivos, existem alguns desafios para a telessaúde na pandemia da Covid-19, alguns deles listados por Ohannessian, Duong e Odone (2020): 1) integração da telessaúde com diretrizes nacionais e internacionais; 2) definição de regulamentação para a prática e estruturas de financiamento; 3) desenvolvimento de diretrizes clínicas com padronização de questionários; 4) elaboração de um plano operacional de orientação aos prestadores do serviço e o incentivo para os usuários aderirem a essa forma de atendimento; 5) kit de ferramentas e condições de comunicação para educar a população quanto ao uso da telessaúde; 6) elaboração de um mecanismo de armazenamento de dados; e 7) avaliação dos impactos dessa estratégia em surtos.

Editora Unijuí - Revista Contexto \& Saúde - ISSN 2176-7114 - v. 21, n. 43, jul./set. 2021 
Este artigo pode mostrar que os indivíduos que compuseram a amostra estavam bem informados sobre a Covid-19 em seus sintomas, formas de transmissão e prevenção. Isso mostra que as estratégias informacionais estão sendo positivas e estão atingindo um público que é de risco para a doença. Nesse aspecto, este estudo confirma a real necessidade da manutenção e atualização das informações passadas na telessaúde e também afirmar o alcance dessas orientações.

Por fim, em relação às limitações do estudo, tem-se o pequeno tamanho amostral e algumas dificuldades quanto às ligações telefônicas. Os idosos não costumam estar perto do telefone celular, e, por vezes, não o escutam tocar, sendo necessário realizar várias chamadas até que eles atendam. Além disso, alguns participantes demonstraram-se introvertidos ou até ocupados com as atividades de casa durante o contato telefônico.

\section{CONCLUSÃO}

A atenção integral à saúde do idoso tornou-se um desafio ainda maior para todos no atual contexto da pandemia da Covid-19. Novas estratégias de cuidado, como a telessaúde, que contemplem as demandas consequentes da epidemia, devem ser consideradas por profissionais e serviços de saúde em geral. Os idosos diabéticos, participantes desta pesquisa, possuíam um adequado conhecimento referente aos sintomas, formas de transmissão e prevenção para a Covid-19. Além disso, esse grupo considerou como extremamente relevante as informações fornecidas pelos pesquisadores sobre esse vírus.

\section{REFERÊNCIAS}

AMORIM, Maria Marta Amancio; RAMOS, Natália; GAZZINELLI, Maria Flavia. Representações sociais das pessoas com diabetes mellitus: implicações no controle glicêmico. Psicologia, Saúde \& Doenças, Lisboa, v. 19, n. 2, p. 293-309, ago. 2018.

ASSOBRAFIR. Comunicação oficial. Recomendação sobre o uso de equipamentos de proteção individual (EPIs) do ambiente hospitalar e prevenção de transmissão cruzada na Covid-19. 2020. Disponível em: https://assobrafir.com.br/wp-content/uploads/2020/04/ ASSOBRAFIR-Covid-19-EPIs_2020.04.15.pdf. Acesso em: 23 maio 2020.

BORNSTEIN, S. R. et al. Practical recommendations for the management of diabetes in patients with Covid-19. The Lancet Diabetes and Endocrinology, v. 8, n. 6, p. 546-550, 2020.

BRASIL. Ministério da Saúde. TeleSUS fará busca ativa de informações sobre coronavírus. 2020a. Disponível em: https://www.saude.gov.br/noticias/agencia-saude/46633-ministerio-da-saude-fara-busca-ativa-de-informacoes-sobre-coronavirus. Acesso em: 23 maio 2020.

BRASIL. Ministério da Saúde. Covid-19. Sobre a doença. 2020b. Disponível em: https:// coronavirus.saude.gov.br/sobre-a-doenca. Acesso em: 23 maio 2020.

BRASIL. Ministério da saúde. 2020c. Disponível em: https://coronavirus.saude.gov.br/sobre-a-doenca\#se-eu-ficar-doente

BRASIL. Ministério da Saúde. Portaria no 2.446, de 11 de novembro de 2014. Redefine a Política Nacional de Promoção da Saúde (PNPS). 2014. Disponível em: http://bvsms. saude.gov.br/bvs/saudelegis/gm/2014/prt2446_11_11_2014.html. Acesso em: 23 maio 2020.

Editora Unijuí - Revista Contexto \& Saúde - ISSN 2176-7114 - v. 21, n. 43, jul./set. 2021 
BULUT, Cemal; KATO, Yasuyuki. Epidemiology of Covid-19. Turkish Journal of Medical Sciences, Turkey, v. 50, n. 1, p. 563-570, Apr. 2020.

CAETANO, Rosangela et al. Desafios e oportunidades para telessaúde em tempos da pandemia pela Covid-19: uma reflexão sobre os espaços e iniciativas no contexto brasileiro. Cadernos de Saúde Pública, Rio de Janeiro, v. 36, n. 5, e000889202020, abr. 2020.

CHAET, Danielle et al. On Ethical and Judicial Affairs American Medical Association. Ethical practice in Telehealth and Telemedicine. Journal of General Internal Medicine, v. 32, n. 10, p. 1.136-1.140, June. 2017.

CODO, Ana C. et al. Elevated Glucose Levels Favor Sars-Cov-2 Infection and Monocyte Response Through a Hif-1 $\alpha$ /Glycolysis Dependent Axis. Cell Metabolism, D-20-00621, May 2020.

GE, Huipeng et al. The epidemiology and clinical information about Covid. European Journal Clinical Microbiology \& Infectious Diseases, v. 39, n. 6, p. 1.011-1.019, Apr. 2020.

GODOY, Arilda Smidt. Pesquisa qualitativa: tipos fundamentais. Revista de Administração de Empresas, São Paulo, v. 35, n. 3, p. 20-29, maio/jun. 1995.

GROSS, Jorge L. et al. Diabetes Melito: diagnóstico, classificação e avaliação do controle glicêmico. Arquivos Brasileiros de Endocrinologia e Metabologia, São Paulo, v. 46, n. 1, p. 16-26, fev. 2002.

GUEDES, Marcelo Barbosa Otoni Gonçalves et al. Apoio social e o cuidado integral à saúde do idoso. Physis, Rio de Janeiro, v. 27, n. 4, p. 1.185-1.204, dez. 2017.

GUPTA, Ritesh; HUSSAIN, Akhtar; MISRA, Anoop. Diabetes and Covid-19: evidence, current status and unanswered research questions. European Journal of Clinical Nutrition, v. 13, p. 1-7, May. 2020.

HAMMERSCHMIDT, Karina Silveira de Almeida; SANTANA, Rosimere Ferreira. Saúde do idoso em tempos de pandemia Covid-19. Cogitare Enfermagem, v. 25, p. e72846-e72846, 2020.

HARAPAN, Harapan et al. Coronavírus disease 2019 (Covid-19): A literature review. Journal of Infection and Public Health, v. 13, n. 5, p. 667-673, May 2020.

KUMAR, Ashish et al. Is diabetes mellitus associated with mortality and severity of Covid-19? A meta-analysis. Diabetes \& Metabolic Syndrome: Clinical Research \& Reviews, v. 14, n. 4, p. 535-545, Apr. 2020.

LI, Long-Quan et al. Covid-19 patients' clinical characteristics, discharge rate, and fatality rate of meta-analysis. Jornal de virologia médica, v. 92, n. 6, p. 577-583, Mar. 2020.

MACKENZIE, John S, SMITH, David W. Covid-19: a novel zoonotic disease caused by a coronavirus from China: what we know and what we don't. Microbiology Australia, v. 41, Mar. 2020

MALLMANN, Danielli Gavião et al. Educação em saúde como principal alternativa para promover a saúde do idoso. Ciência \& Saúde Coletiva, Rio de Janeiro, v. 20, n. 6, p. 1.7631.772, June 2015.

NASCIMENTO, Israel et al. Novel Coronavirus Infection (Covid-19) in Humans: A Scoping Review and Meta-Analysis. Journal Clinical Medicine, v. 9, n. 4, p. 941, Mar. 2020.

OHANNESSIAN, Robin; DUONG, Tu Anh; ODONE, Anna. Global telemedicine implementation and integration within health systems to fight the Covid-19 pandemic: a call to action. JMIR Public Health and Surveillance, v. 6, n. 2, p. e18810, Abr. 2020.

PAL, Rimesh; BHADADA, Sanjay K. Covid-19 and diabetes mellitus: An unholy interaction of two pandemics. Diabetes \& Metabolic Syndrome: Clinical Research \& Reviews, v. 14, n. 4, p. 513-517, Apr. 2020.

PERIC, Slobodan; STULNIG, Thomas M. Diabetes and Covid-19. Wien Klin Wochenschr, v. 132, n. 9-10, May. 2020.

PRAIS, Jacqueline Lidiane de Souza; ROSA, Vanderley Flor. Nuvem de palavras e mapa conceitual: estratégias e recursos tecnológicos na prática pedagógica. Nuances: Estudos Sobre Educação, Presidente Prudente, v. 28, n. 1, p. 201-219, jan./abr. 2017. 
RICHARDSON, Safiya et al. Presenting Characteristics, Comorbidities, and Outcomes Among 5700 Patients Hospitalized With Covid-19 in the New York City Area. Journal of the American Medical Association, v. 323, n. 20, p. 2.052-2.059, Apr. 2020.

ROSIQUE-ESTEBAN, Nuria et al. Cross-sectional associations of objectively-measured sleep characteristics with obesity and type 2 diabetes in the PREDIMED-Plus trial. Sleep, v. 41, n. 12, Dec. 2018.

SANAR MED. Liga Acadêmica de Infectologia. Coronavírus: características, fisiopatogenia, mapa mental e mais. 2020. Disponível em: https://www.sanarmed.com/resumos-a-familia-dos-coronavirus-e-o-novo-representante-abordagem-sobre-o-sars-cov-2-ligas. Acesso em: 23 maio 2020.

SANTOS, Alaneir de Fátima et al. Uma visão panorâmica das ações de telessaúde na América Latina. Revista Panamericana de Salud Pública, v. 35, n. 5-6, p. 465-70, 2014.

SHIGEKAWA, Erin et al. The Current State Of Telehealth Evidence: A Rapid Review. Health Aff (Millwood), v. 37, n. 12, p. 1.975-1.982, Dec. 2018.

SINGHAL, Tanu. A review of Coronavirus Disease-2019 (Covid-19). The Indian Journal of Pediatric, v. 87, p. 281-286, Apr. 2020.

SBD. Sociedade Brasileira de Diabetes. Notas de esclarecimento da Sociedade Brasileira de Diabetes sobre o coronavírus (Covid-19). O Diabetes no cenário da pandemia de Sars-Cov-2. 2020a. Disponível em: https://www.diabetes.org.br/publico/notas-de-esclarecimentos-da-sociedade-brasileira-de-diabetes-sobre-o-coronavirus-covid-19/2060-o-diabetes-no-cenario-da-pandemia-de-sars-cov-2. Acesso em: 23 maio 2020.

SBD. Sociedade Brasileira de Diabetes. Isolamento social, higienização de mãos e uso de equipamentos de proteção individual contra o coronavírus (Covid-19) - informações para a população geral e população com diabetes. 2020b. Disponível em: https://www.diabetes.org.br/covid-19/isolamento-social-higienizacao-de-maos-e-uso-de-equipamentos-de-protecao-individual-contra-o-coronavirus-covid-19-informacoes-para-a-populacao-geral-e-populacao-com-diabetes/. Acesso em: 25 maio 2020.

SBD. Sociedade Brasileira de Diabetes. Gerenciamento do DM1 de início recente por telemedicina. 2020c. Disponível em: https://www.diabetes.org.br/diabetes/gerenciamento-do-dm1-de-inicio-recente-por-telemedicina/. Acesso em: 24 maio 2020.

SOHRABI, Catrin et al. Corrigendum to "World Health Organization declares Global Emergency: A review of the 2019 Novel Coronavirus (Covid-19)". International Journal of Surgery, v. 76, p. 71-76, May. 2020.

TESTINO, Gianni. Are patients with alcohol use disorders at increased risk for Covid-19 infection? Alcohol and Alcoholism, v. 0, n. 0, p. 1-3, May. 2020.

TIAN, Huaiyu et al. An investigation of transmission control measures during the first 50 days of the Covid-19 epidemic in China. Science, v. 368, n. 6.491, p. 638-642, May. 2020. TUCKSON, Redd V. et al. Telehealth. The New England Journal of Medicine, v. 377, n. 16, p. 1.585-1.592, Oct. 2019.

VELAVAN, Thirumalaisamy P.; MEYER, Christian G. The Covid-19 epidemic. Tropical Medicine and International Health, v. 25, n. 3, p. 278-280, mar. 2020.

WANG, Aihong et al. Timely blood glucose management for the outbreak of 2019 novel coronavirus disease (Covid-19) is urgently needed. Diabetes Research and Clinical Practice, v. 162, p. 108-118, Apr. 2020.

WHO. World Health Organization et al. Telemedicine: opportunities and developments in member states. Second edition. Geneva, Switzerland: Global Observatory for eHealth series, 2010.

WHO. World Health Organization. WHO Coronavirus Disease (Covid-19) Dashboard. 2020. Disponível em: https://covid19.who.int/. Acesso em: 26 May. 2020.

YAN, Carol H. et al. Association of chemosensory dysfunction and Covid-19 in patients presenting with influenza-like symptoms. International Forum Allergy \& Rhinology, v. 0 , n. 0, Apr. 2020. 
YONGHYUN, Lee et al. Prevalence and Duration of Acute Loss of Smell or Taste in Covid-19 Patients. Journal of Korean Medical Science, v. 35, n. 18, p. e174, May. 2020.

YUN, Sun et al. The Effectiveness and Cost of Lifestyle Interventions Including Nutrition Education for Diabetes Prevention: A Systematic Review and Meta-Analysis. Journal of the Academy of Nutrition and Dietetics, v. 117, n. 3, p. 404-421, Mar. 2017.

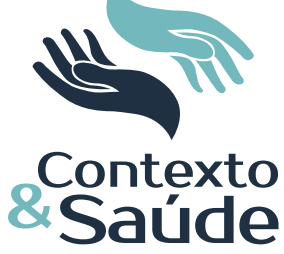

